\title{
Revitalization of Cultural and Aesthetical Assets of Iranian Traditional Bazaar
}

\section{Maryam Ziyaee ${ }^{\star}$}

\begin{abstract}
In recent decades, modernization is extensively changing the face of Iranian cities. Besides, urban places are losing their traditional features, identity and cultural characteristics. Conservation of cultural heritage resources may rescue historical parts of the cities; hence, other traditional urban spaces do not receive enough attention and protection due to economic concerns. Mashhad, as one of the main religious touristic destinations in Iran, is unfortunately losing its traditional features due to extensive attractions of physical transformations. Economic profits fascinating constructions into the city center of Mashhad, specially surrounding areas of the holly shrine. This issue has been led to demolishment of the old texture of the city center. Sarshoor bazaar is one of rescued traditional urban public spaces in city center of Mashhad with typical characteristics of an Iranian ancient bazaar. This study mainly focuses on cultural and aesthetical patterns of traditional Iranian bazaars in order to provide a conceptual strategy for revitalization of Sarshoor bazaar. To this aim, a theoretical review is provided through main representative factors of cultural landscape to decide about a proper strategy for improving cultural quality of the selected case study. We also provide a practical analysis through social and behavioral patterns of the citizens and pilgrims in public spaces to realize material and immaterial features of Sarshoor bazaar, and
\end{abstract}

Keywords: Cultural identity, cultural landscape, transformation of city center, Iranian traditional bazaar.

*PhD in Urban and Architectural Design, Department of Architecture and Urban Studies(DASTU), Politecnico di Milano, Italy. Email: maryam.ziyaee@polimi.it Orcid ID: http://orcid.org/0000-0002-6748181X 
consequently, find out any possible opportunity of improving tangible and intangible characteristics of this case study area.

To capture cultural landscape qualities of Sarshoor bazaar, a final design is provided to envelope a light traditional surface representing the visual landscape of the bazaar. Main passage and piazzas are also equipped for the movements of pilgrims and setting up annual traditional and social events.

\section{INTRODUCTION}

The importance of heritage sites, heritage objects and even relics comes fundamentally from their identities which have been gained their values through the time. Identity by definition is the representative quality of a phenomenon that clearly describes the corresponding inner characteristics. Cities as physical creation results of the human civilization have lots of different factors that altogether manifest their identities. In accordance, buildings, spaces and people take the main roles in representing the story of the urban identities. All historical cities around the word have their own sufficient footprints declaring identity of the place to citizens as well as other visitors. Concerning aforesaid notion, we argue that cultural landscape of urban public spaces in a city, can reflect art, culture and belief of the past generations which is shaped through the time. Through modernization era, identity is the missing characteristic of contemporary cities. Iranian cities are significant examples which have been faced prompt transformations of traditional places through attraction of some modern structures in recent decades. We analyze here loss of identity in urban spaces of Iranian contemporary city centers to possibly provide an applicable solution for the lack of identity.

Sarshoor bazaar is an example of traditional urban spaces which is dealing with unsuccessful urban regenerations due to the force of planning modern transformations of Mashhad city center. Unfortunately, recent extensive demolishment of old texture of Mashhad city center is not only destroying thousands years old physical features of urban spaces, but also changing cultural aspects of the users. Results of such destructive decision can be clearly realized from fragmented landscape structure of the city center without any logical connections, either inside itself, or to the other zones of the city. Accordingly, public spaces in the city center are turning to become some isolated regions without any cultural and historical solidarity that provides no identity to the users.

This work tries to discuss visual and semantical connections between past and present of urban public spaces to revitalize identity of the place. To this end, we will analyze factors of cultural 
landscape through traditional Iranian bazaars. Accordingly the paper is structured into three main sections of: $(i)$ theoretical studies through cultural identity, and (ii), the characteristics of Iranian traditional bazaar and (iii) a case practical analysis through revitalization of cultural landscape in city center of Mashhad. Theoretical part comprises a comprehensive study through cultural landscape and its representative factors. We also discuss characteristics of the Iranian bazaars as one of the main resources of cultural heritage from ancient Iranian city centers. The result of this part enriches a strategy for preserving identity of the selected case study. Practical section provides analysis of cultural landscape aspects of the old texture of Mashhad city center. Our intervention precisely concerns refurbishment of the Sarshoor traditional bazaar in Mashhad city center from the cultural point of view.

\section{URBAN CULTURAL LANDSCAPE}

The origin of cultural landscape theoretically overlaps with the theory of urban morphology and practically arises from the studies of the urban geography (Calcating, 2012). The term "cultural landscape" was firstly used by the German geographer, Schlüter (O'hare, 1997). To him, landscape classifies to: (i) the original and (ii) the manmade landscapes (Calcating, 2012). Other early researches also have been explained cultural landscape as some patterns created through physical environments by human activities and cultural systems (Whitehand, 2007). More recently, UNESCO (2008) provided a definition of cultural landscapes as the cultural properties representing the "combined works of the nature and of the man". Such properties are illustrative of the evolution of human society and settlement over time, under the influence of the physical constraints and/or opportunities presented by their natural environment and of successive social, economic and cultural forces, both external and internal.

Ziyaee (2017) clearly discussed the components of cultural landscape in terms of: (i) Material and (ii) Immaterial features (see Fig. 1). Materials are composed of the physical and visible components of the cultural landscapes. A landscape can also be seen as a cultural landscape from a spiritual or symbolic point of view, even if it has nonvisible. On the other hand, immaterial can generally represent nonvisible characteristics of the place. The 'immaterial' feature of each cultural landscape is the sprite of that place, a nostalgic spatial image of each culture which is implemented through some cultural values, cultural manners or cultural events. 
Figure 1. Main components of characterizing "Cultural landscape"

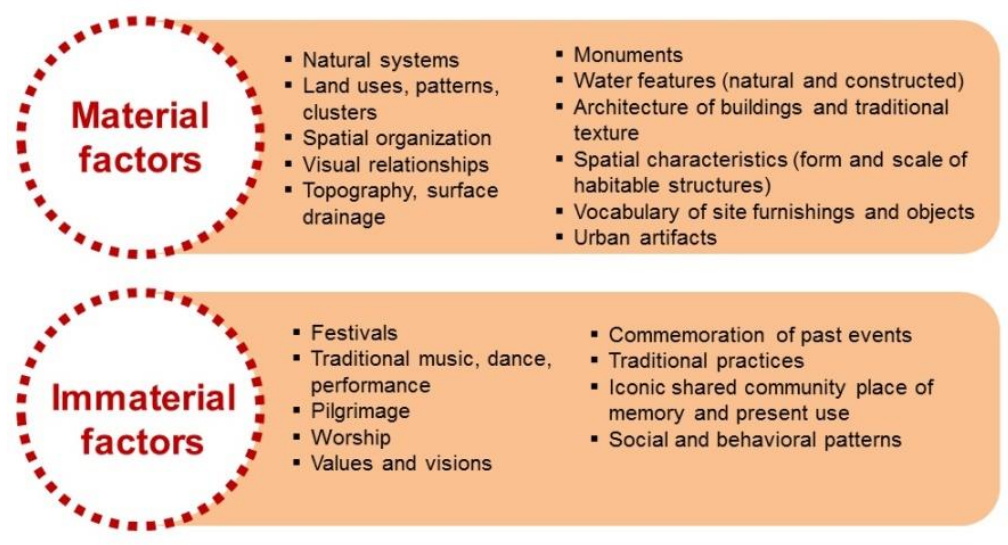

Cultural characteristics of urban landscape are representative source of the place identity. Accordingly, it would not be exaggerating if we say that urban identity is the way of presenting natural, cultural and manmade components of a city. Furthermore, the cultural identity of a city has to be understood as a whole system of social and physical values of the place (Hough, 1990). These factors altogether makes a place different from the others (Kaymaz, 2013). The concept of urban identity has spatial, social, cultural and economic dimensions and process both in macro and micro environments. These components should be managed in a comprehensive totalitarian approach as a system.

Historical city centers are main sources of urban identity, memory and belonging (Ertan, 2016). They can provide users aesthetic portray from the history of the city which is consists of different social, cultural, political, psychological, emotional and architectural aspects. Identity of the historic city centers could tell the stories of the cities and their users. Then, protection of these valuable areas should be promoted through the entire contemporary development project inside central part of the cities.

A successful transformation of the historic city centers requires integration of urban regeneration regulation for cultural, social and economic sides that are working well together. Regeneration of historic city centers includes conserving history and culture while protecting also viability of the place (Ertan, 2016).

Urban areas have been entirely transformed in recent era and it is critical how to link identity of the contemporary cities to their historical values (Carmona et al, 2010). Our surrounding social, cultural and physical environments are extensively affected by two major phenomena of modernization and globalization. Then, traditional patterns of historical city centers are violently under the threat of globalization. Relph (1976) describes this phenomenon by defining the concept of "placelessness". To him, 
placelessness refers to the loss of the spirit of the places which leads to the death of local identity among modern constructions.

Modern architecture changed the facade of urban public spaces by inviting automobiles, infrastructures and industrial buildings to the cities. Then, creation of so called "industrial cultures" undeniably changed our perception from the urban places and their cultural landscapes.

Following sections provide characteristics of the Iranian Bazaar as a traditional public space and analyzes a case study from cultural landscape point of view.

\section{TRADITIONAL IRANIAN BAZAARS}

Traditional Iranian cities generally have been followed compact, concentrated and homogeneous structures. Looking to spatial patterns and physical morphology of traditional Iranian cities demonstrate that there were some important factors such as: (i) physical environment plateau to trade, (ii) historical events and (iii) religious, social and political structure of the country which had strong influences on emerging and development of Iranian cities (Kheirabadi, 1991).

Transformation of the Iranian medium cities to the new metropolitan cities started from the $20^{\text {th }}$ century. From then, Iranian cities have been expanded by and large to response to the rapid population growth. Then, spatial patterns of the Iranian contemporary cities have significant differences from their traditional ones. Also, social stratification and diversity in land uses, employment, immigration, and crowd have been caused some emerging complexity of urban area in contemporary era (Madanipour, 1998).

Accordingly, recent developments of Iranian urban areas have been forcefully influenced by globalization and modernization (see Madanipour, 1998 for details) which generally emphasize the role of the state in city development rather than traditional rules of shaping and managing Iranian local urban affairs. This type of urban transformation had more destructive effects on the old traditional areas like bazaars. 
Figure 2. Transformation of Iranian cities. Median Era: $5^{\text {th }}$ century BC, Parthan: $3^{\text {th }}$ century BC, Sassanid Era: from $3^{\text {th }}$ to $7^{\text {th }}$ centuries, Primary Islamic Era: From $7^{\text {th }}$ to $11^{\text {th }}$ centuries, Seljuk Era: $12^{\text {th }}$ century, Safavi Era: $17^{\text {th }}$ and $18^{\text {th }}$ centuries, Old Tehran in $19^{\text {th }}$ century (Habibi, 2001).

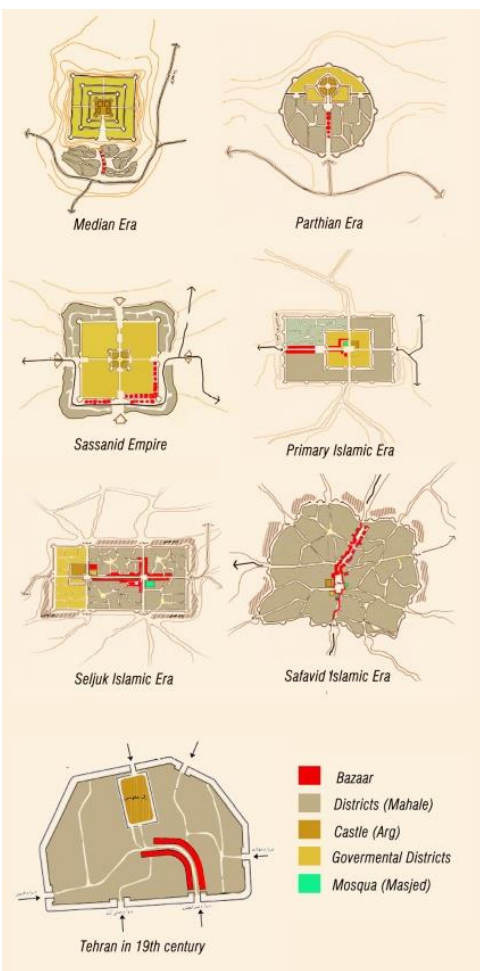

Iranian bazaars have been active urban spaces with clear patterns which have been kept the history and the memory of different generations inside itself. The continuity and the unity of bazaars through the time have been kept this masterpiece of construction as cultural place for decades.

Habibi (2001) made a comprehensive work on forms and society of Iranian cities from the very first Persian civilization era to the Islamic era. Fig. 2 is representing changes in the graphical shapes of the traditional Iranian cities through the history. Schemes clearly show that bazaars had a central situation in the settlement texture of the city to play an important passageway role. Hence, Habibi (2001) discussed that the position of bazaar in Iranian communities had been changed through the time due to the changes in structure of the cities. In Median era, the embryonic stage bazaar had been shaped between castle and the main urban link road through the districts. In Parthian era, the bazaar had been followed the area along the main road from the city gate to the downtown. Bazaar was the heart of the city in the Sassanid period and served as the backbone of towns. From then, the plaza connected to the bazaar changed into a place for socio-economic activities. The bazaar during the early Islamic era and to some extent in Seljuki era has been still designed in the Sassanid method. In this period, bazaars were important for city formation and structure. 
There were some general concepts (from urban scale) and some detailed concepts (from the architectural scale) to relate the functions and decorate of the place to the façade of the bazaar.

In general, a bazaar has been consisted of a main passage (Rasteh Bazaar) with different buildings attached to it. The length and the scale of the bazaar were depended to the size of the cities and the corresponding urban economic powers (Soltanzade, 2004). It has been always comprised of simple four-vaulted spaces (ChaharTaqi) with two chambers on sides. In contrary to this repeated symmetry, attached buildings to the main passage were very different including kinds of governmental, commercial, religious, educational and service buildings. The commercial buildings are considered to be the essential part of the bazaar (Haji Qassemi, 2005). According to Pourjafar (2014) and Soltanzade (2004) the primary elements of the bazaar are the "Rasteh" (bazaar streets), "Saray" (is a kind of corridors which are worked as passage parallel to the Rasteh), "Dokkan" (shops), "Hojreh" (small shops), "Tim" and "Timcheh" (most of the commercial offices of expensive products like Persian carpets were situated in Tim or Timche), "Qaysariye" (some Saray or Carvansaray or Timche that presented lux-products like gold and silks jewelries), "Chaharsouq" (the intersection of two main Rasteh), and "Carvansarai" (is a loading place for the coming carvans). The secondary elements are the "Masjed" (mosque), "Madreseh" (school), and "Hammam" (bath house) (see Fig. 3).
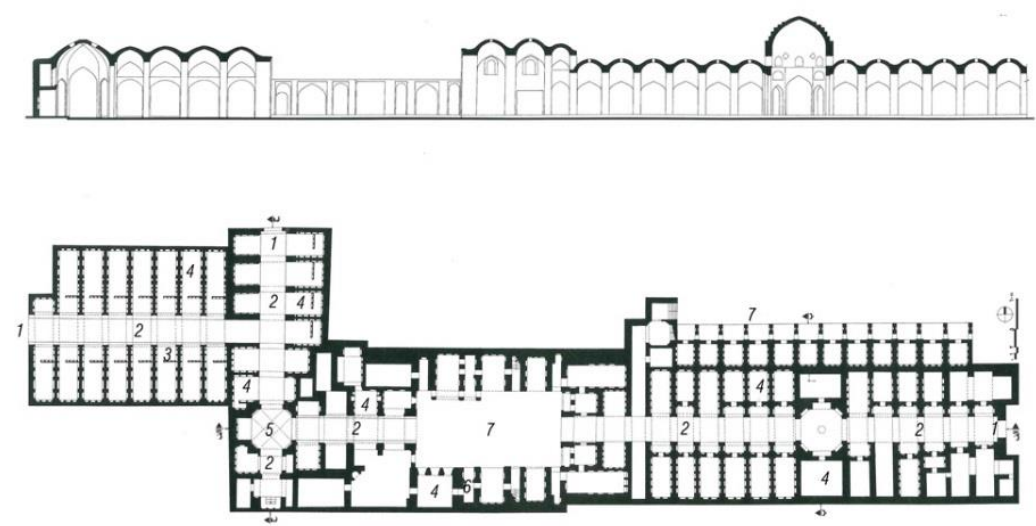

Some simple elements and unique modulus has been used in the architecture of traditional bazaars aiming to create spatial values of integration, harmony, balance, visual mobility, symmetry, legibility, lighting, privacy and hierarchy that altogether make the power of these masterpiece constructions (Fig. 4).
Figure 3. Traditional bazaar of Bam city, the main spaces: 1 . Entrance, 2. Corridor (Raste), 3. Eivanche (small platform), 4. Chamber (Dokan), 5. Chaharsouq $6 . \quad$ Courtyard (HajiQassemi, 2005) 
Figure 4. Traditional bazaar of Qum city, Iran representing physical structure, aesthetical values and a sense of unity through the whole construction.

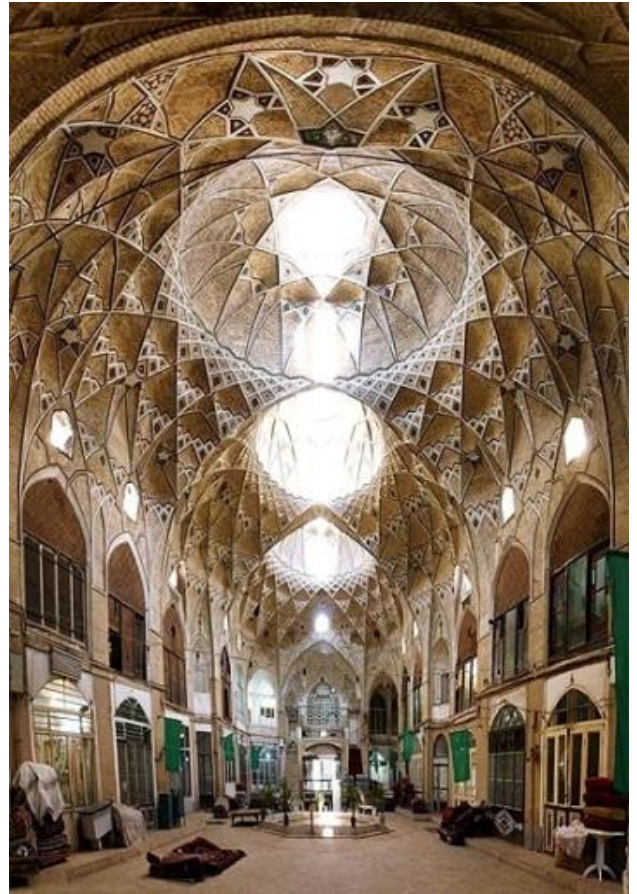

The hierarchy system of connecting space together makes the sense of movement inside the collection of bazaar. The beauty of mixing different open and close spaces through bazaar makes unique spaces for users visually and functionally. The land had an irregular but geometric, right angle shape. All parts of the bazaar follow the same geometric order. This order was characterized by the unchanging rhythm of the spans and the parallelism of the walls. This unity has resulted in some of the chambers filling entirely one side of the corridors (Haji Qassemi, 2005).

The main immaterial landscape of Iranian bazaar could be described by the sense of unity in both physical and nonphysical aspects. Bazaar was a place for making unity in the religious and social behaviors of citizens as well as the quality of their routine life. Each brick of the constructions in bazaars had specific meanings inside their colors, lighting and all their aesthetic patterns. From architectural point of view, these symbols are parts of the traditional Iranian society and represent the ideology and lifestyle of the users. This unity has been made a visual and spiritual identity of the Iranian bazaar from the urban aspects.

Bazaars have been also played an essential religious, cultural, social, and political role in Iranian cities. Besides, bazaars have been places of celebrating important political and/or religious events (Mehdipour, 2013). All elements and principles of traditional bazaar have been providing a message of "unity" for their users. This unity in comprehensive urban dimensions easily has been made the visual and spiritual identity of Iranian bazaar. 
Bazaar was a place for most of social, political and cultural activities and had important role in the economic and civic activities of the citizens. The identity of traditional Iranian cities is connected to the existence of bazaars as the main objects of spatial structures of the cities (Pourjafar, 2014).

The functions of bazaars were more than commercial areas in the city. All social, political, cultural aspects of the cities were affected by the activities in the bazaar. Functional characteristics of bazaar have been provided connection between different parts of the cities. Network of main corridors of bazaar, small meydans, entrances and tiny roads that branched from the main corridors make the cohesion of the system through the cities (Pourjafar, 2014).

In 20th century, automobile bring new forms of accessibility and movement to the Iranian cities and made important changes in the size of streets and traditional structure of the cities (Tafahomi, 2007). Through such physically growth of urban elements, most of the public urban spaces are lost in different layers of the urban transformations.

\section{SARSHOOR BAZAAR IN CITY CENTER OF MASHHAD}

Mashhad is annually the destination of a large number of people because of its religious and historical values. This city is one of the most important cities of Iran from its religious, economic and population (with near 3 million inhabitance) point of view (Mashhad Municipality, 2012). A holly shrine for shie-Muslims is located in the city center of Mashhad which is the main reason of developing this city. Spatial domain of the city has been expanded through different physical zones with different historical periods of time (see Fig. 5). 
Figure 5. he spatial development of Mashhad city

(Farhoodi et al, 2013); reworked.
Figure 6. Diffrent urban textures of Mashhad city.

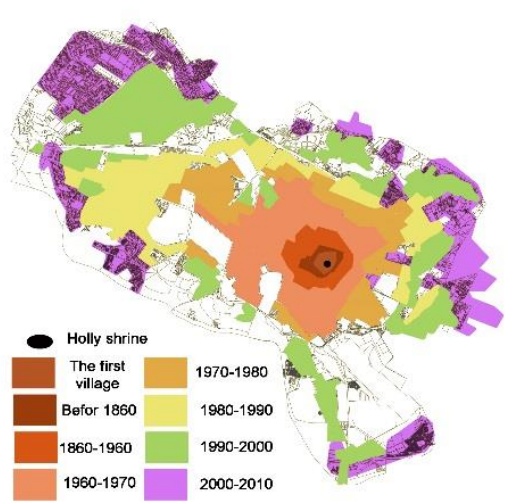

More precisely, Mashhad can be divided into four different physical textures of: (i) traditional, (ii) intermediate, (iii) suburb and (iv) new contexts (see Fig. 6). The traditional part situated in the city center surrounding the holly shrine. This part has an organic structure which is shaped since 9th century A.D. The intermediate context involves some mixed forms of organized and organic structures. Buildings are mostly constructed here since 1960. The western zone of Mashhad city contains recently constructed streets, highways, modern buildings, towers and shopping malls. And finally, suburb areas are made up of some rural settlements melted in the urban texture during last decades (Ziyaee, 2009).

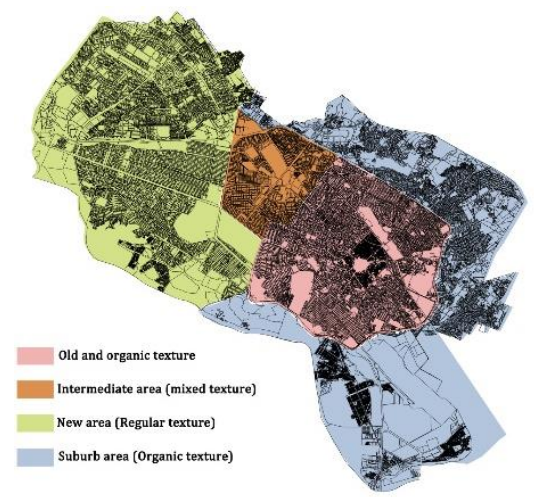

The modernization and the economical profits are two main resources of the changes in the old fabric structure of Mashhad city. The transition from tradition to the modernity has been led to a comprehensive urban transformation in the city center of Mashhad. Fig. 7 shows the main procedure of urban transformation in Mashhad. Such transformation has been led to the loss of valuable historic texture of Mashhad city center, particularly, around the holly shrine. 


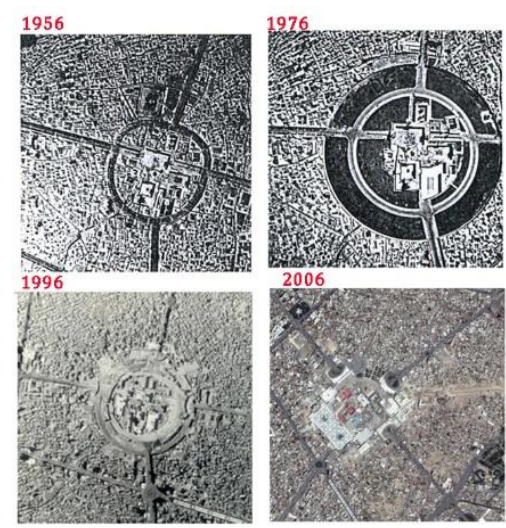

Most buildings in central parts of the city are gradually transformed to the commercial sectors. Accordingly, spatial structure of Mashhad's city center became a powerful economical market for pilgrim services. This reconfiguration have been implemented through a comprehensive new master plan of Mashhad, Khazeni comprehensive plan (1967-1992) and Mehrazan comprehensive master plan (1992-2012) approved by municipality of Mashhad (Farnahad Consulting Engineers, 2011). Later on, an enormous reconstruction project of the Mashhad city center started to detail such planning (Tash, 2006). According to this planning project, surrounding areas of the Holly Shrine will be isolated by a green belt and the rest of the old district should be transformed to some modern shopping malls, hotels and residential towers (Fig. 8). Then, the only remaining traditional texture of the city is the one situated around Holly Shrine. Such physical structures are valuable resources representing the urban history of Mashhad.
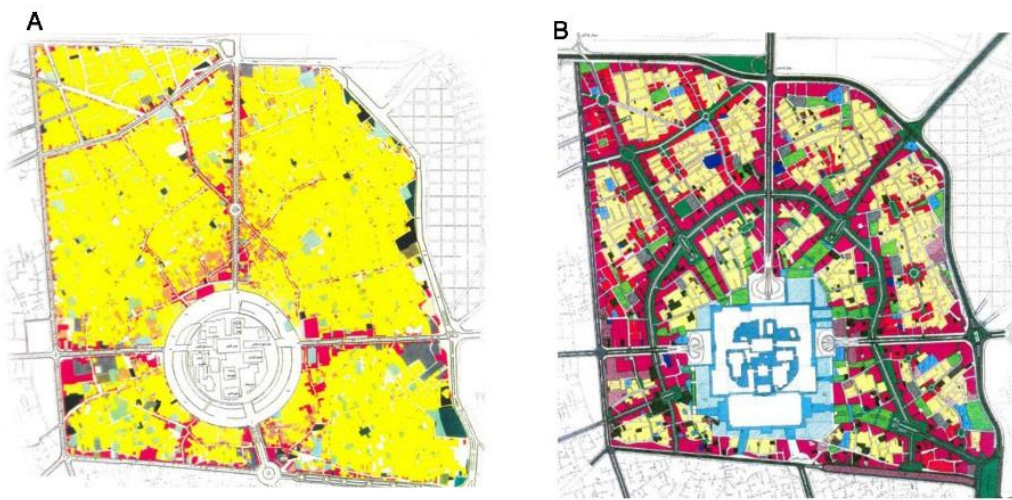

Within 19th century, most areas around holly shrine were reconstructed and developed. As a result, main bazaar of Mashhad divided into two parts and the southern part named Sarshoor (Rezvani, 2005). Sarshoor district is one of the oldest areas of Mashhad that is recently subjected to the planning of some structural modern changes. This district is well-known because of a passage and traditional bazaar going along the main part of this district (see Fig. 9). Although the physical structure of the original
Figure 7. Transformation of the old texture of the Mashhad city center.

Figure 8. A; the original morphology of the city center and B: the approved new transformation master plan of 
bazaar is changed through the time, the memory and the sense of traditional bazaar is still alive there. From the history of this bazaar it is indicated that there were lots of Hammams (traditional public bathrooms) and Caravansaries situated along this bazaar because, by culture, pilgrims needed to take a bath before entering to the Holly Shrine (Zarabadi and Ziyaee, 2008).

Figure 9. The original bazaar of the Mashhad before transformation.
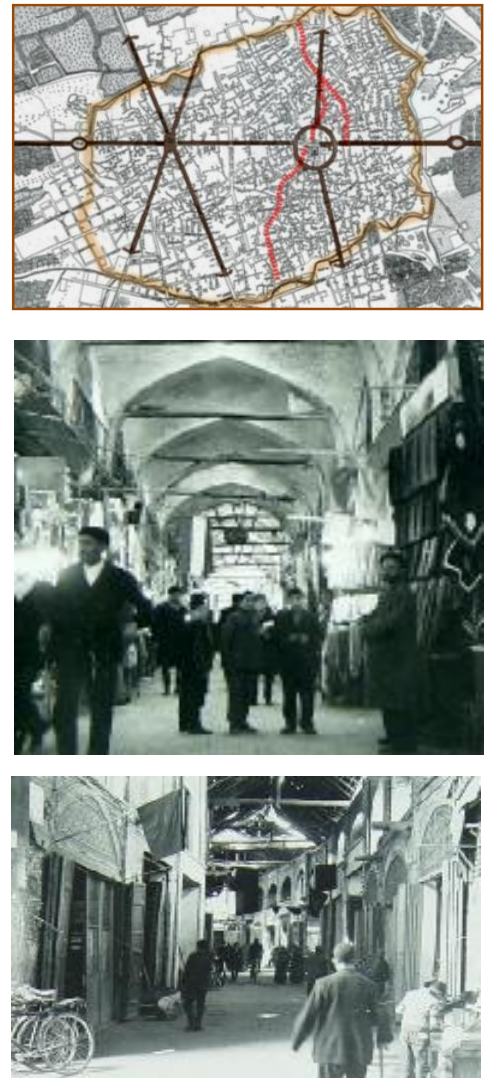

Next section assesses structural characteristics of Sarshoor bazaar through a cultural landscape analysis of materials and immaterials. It is proposed that the result of this part could helpful to capture and possibly improve cultural identity of the case study.

\section{MATERIAL FEATURES OF THE TEST CASE}

From physical and aesthetical point of view, the shape of Sarshoor bazaar follows the general pattern of Iranian bazaars while including several chambers around a main passage. It is ceiling and covered by traditional materials and schemes (Rezvani, 2005). Fig. 10 shows a serial vision survey through the bazaar that could help us to recognition the physical structure of it in contemporary situation. According to our investigations, main material factors of this bazaar are listed as bellow:

- there are different zones for commercial activities and pilgrims services 
- interference of the pedestrian passages and cars movement

- variety of forms, sizes and shapes of buildings is clear

- rarely designed façade

- crowd of awnings

- no brief landmarks through passages

- main open spaces are generally occupied as vehicle parking

- traditional shops and their vitrines are still alive here

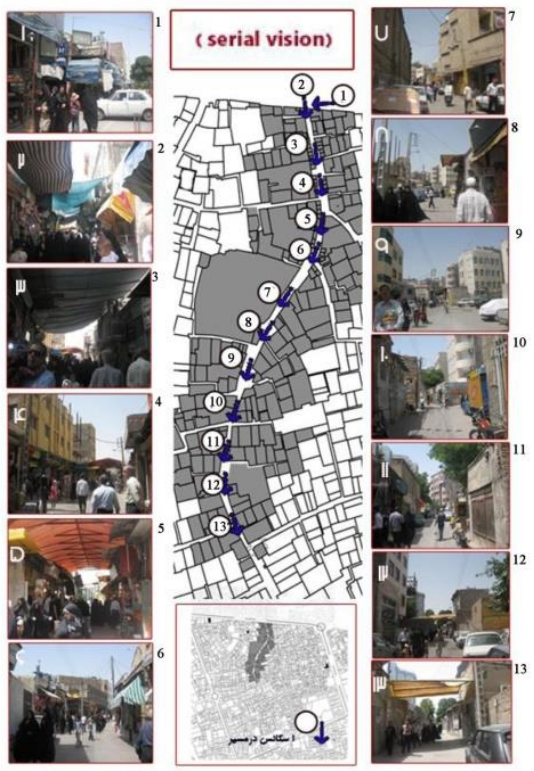

We, generally, see that recent situation of Sarshoor bazaar confirms weekly protection of the traditional physical elements in studied case study.

\section{IMMATERIAL FEATURES OF THE TEST CASE}

The immaterial factors of this case study mainly include some traditional religious programs that are annually setting up in urban public spaces of Iranian cities. Sarshoor bazaar is also an important place for the following social main activities:

- "Ashura" which is a kind of mourning for the third leader of Shia-Muslims

- Traditional "Nazri" as a social activity of preparing gratis food and offering to the pedestrians

- "Tazie-khani" is a kind of traditional theater as a social and traditional pattern from the past which are rarely existed now.

Fig. 11 represents the direction of religious movement programs through Sarshour bazaar. Fig. 12 also represents behavioral patterns of the users along main Sarshoor bazaar passage. High
Figure 10. A serial vision survey of the Sarshoor bazaar. 
number of pedestrian movements is considered in the northern entrance of the bazaar as well as the middle parts.

Figure 11. Movement passage of the religious program in Sarshoor bazaar ending to the holly shrine.
Figure 12. The Behavioral pattern of users through the bazaar.

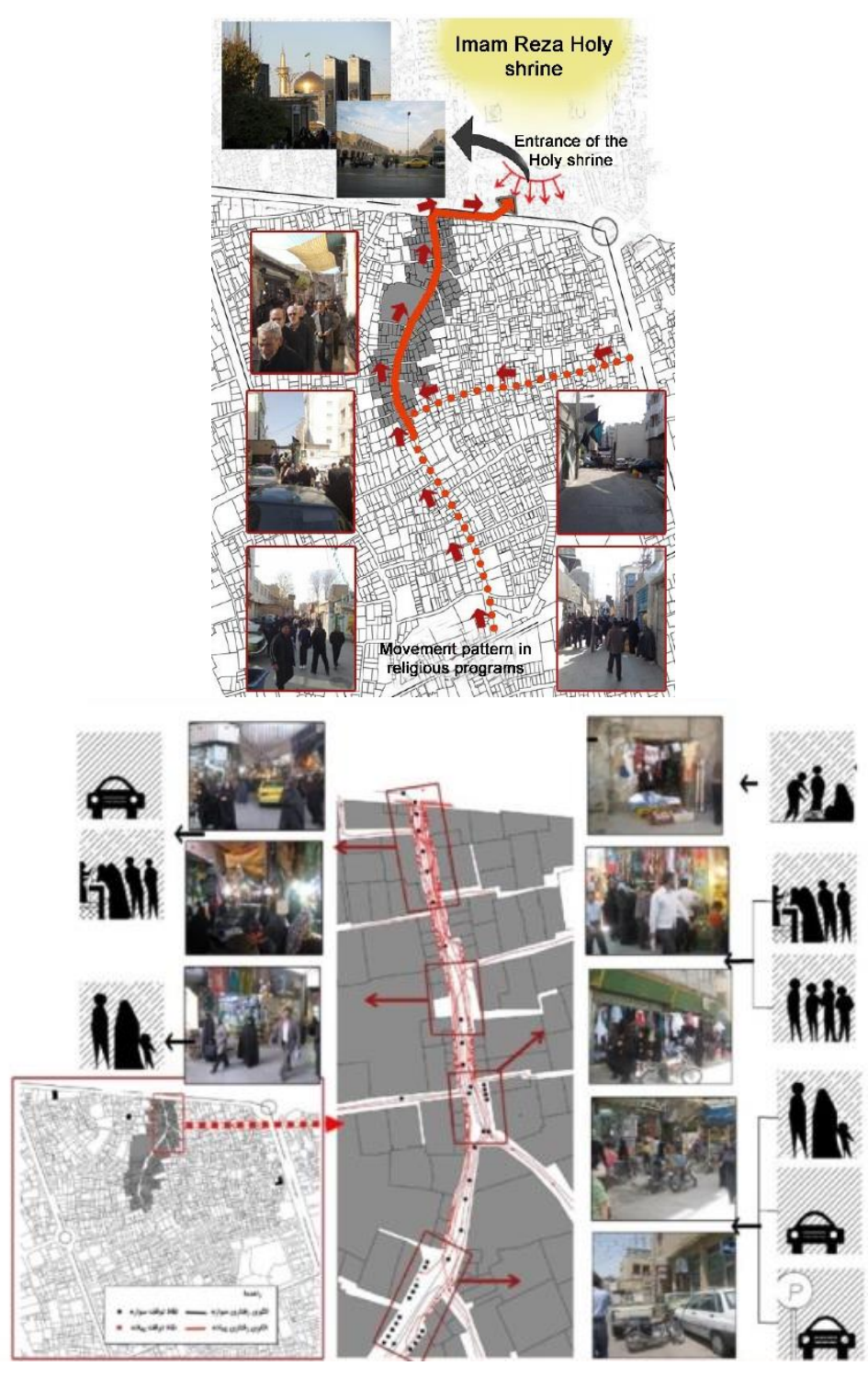

Fig. 13 represents a comprehensive analysis of physical and nonphysical characteristics of the Sarshoor bazaar. This map presented different important functional zones in the bazaar including: (i) the commercial parts which are mostly crowded around northern entrance of the bazaar, (ii) the traditional residential areas, (iii) the hostels and touristic apartments. There are also two abandoned spaces through the case study that are now using as parking spaces. These spaces are situated beside local streets and have enough potential for transfering to the small piazza as traditional chaharsooghs in original bazaar. 


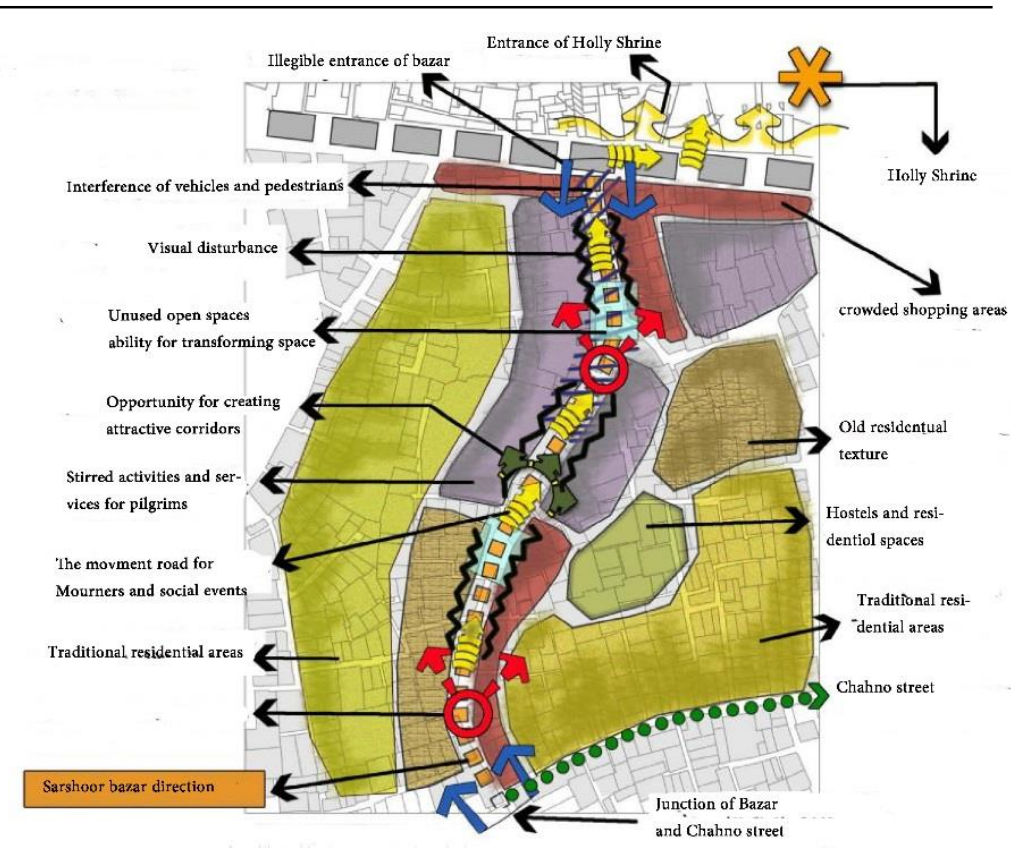

Figure 13. The analaysis map of the Sarshoor bazaar

\section{STRATEGY AND CONCEPTUAL DESIGN}

As we analyzed in previous section most of physical structures of studied bazaar does not provide any clear aesthetical qualities even in pavement and urban furniture. Accordingly, our suggested strategy of preserving lost identity of Sarshoor bazaar attentions to reconstructing façade and decorating open spaces and facilities of the case study. Our main goal here is keeping coherence of the structure and visual patterns of the Iranian bazaar. Secondly, proposing plan should have opportunity of protecting social and religious characteristics of this bazaar. The medium intervention to create better commercial units along the bazaar could bring the sense of traditional activities in addition to improving visual identity of the bazaar.

According to the final proposed plan, material features of the bazaar can be improved by keeping the organic structure of the bazaar route. Two main junctions through the main passage are transformed to the small piazzas. The entrances of the bazaar will increase the sense of invitation for the users (see Fig. 14). 
Figure 14. The phisical and functional concept for refurbishment of Sarshoor bazaar.
Figure 15. The detailed architectural design for the entrance of the bazaar.

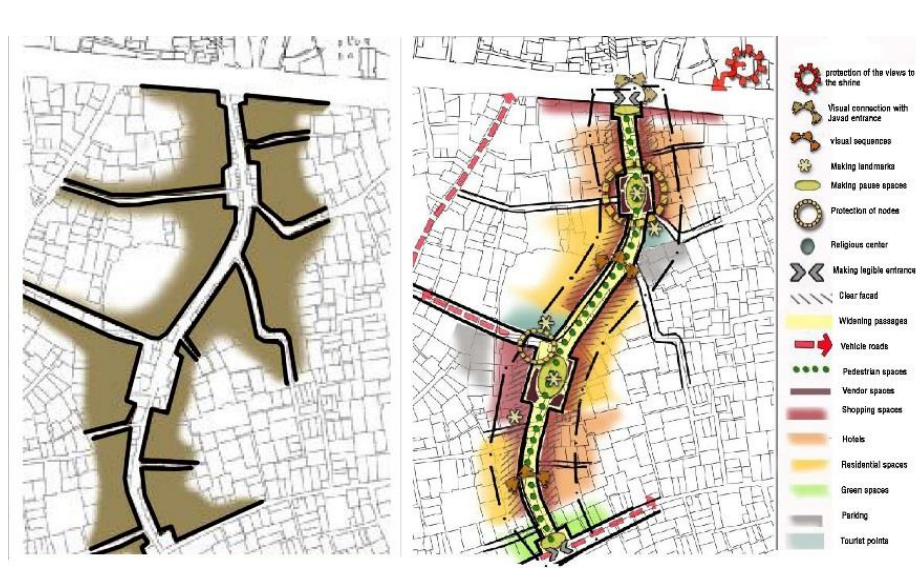

As there are not any existence roofs in the physical fabric of the bazaar and it is also costly to construct them, it is suggested to improve the sense of enclosure by creating some semi-enclosed corridors along the bazaar's pathway. Also it is suggested to use the traditional and nostalgic scheme of Iranian architecture for decorating the facade of the 1st and 2nd floors. Fig. 15 shows a proposed section for reconstruction of the bazaar. The whole space of bazaar should be dedicated to the pedestrian movement. Then, immaterial quality of the space will improve by setting up some social activities through this safe area. Some traditional materials with symbolic patterns are also suggested for the pavements and urban furniture. Furthermore, the two proposed piazzas are equipped with the theatrical platforms possibly assigning to the social and religious programs.

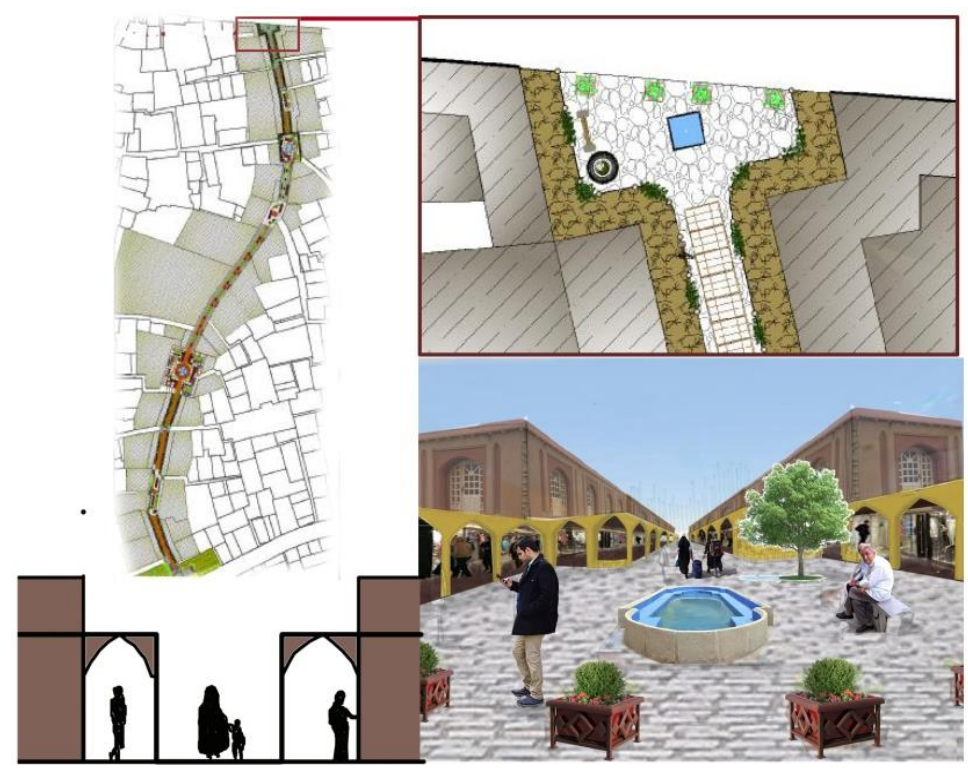

In order to response to the need of touristic services in the territorial areas around the holly shrine, the land use in both sides of the bazaar are dedicated to commercial and residential (e.g. hotels) functions. Then hotels and residential services could be situated in the above floors of the bazaar. 


\section{CONCLUSIONS}

Within modernization of the cities in recent era, transformation of traditional city centers may face some gaps of cultural identity. We studied representative elements of cultural landscape for Sarshoor bazaar in Iran to capture identity of the place through any future transformation of this area. Precisely speaking, we assessed a suite of "material" and "immaterial" features of cultural landscape through Sarshoor bazaar aiming to detect, protect and possibly refurbish missed cultural identity of the studied place. Analysis generally noticed: (i) capability of the case study for performing social and religious programs and (ii) physical patterns of traditional Iranian bazaar can capture cultural identity of the place through transformation process.

Our practical analysis for Sarshoor bazaar in Iran suggests that cultural landscape of this study area can be improved by some modification of the façade and open spaces through the passage area. To this end, coherency of the visual and physical elements and safety of the pedestrians are also considered. Then, improving connections and sequences of different open spaces can stand as a solution for revitalization of urban identity through studied area.

\section{REFERENCE}

Carmona, M. Tiesdell, S and Heath, S. Oc. T. ( 2010). Public Place Urban Space, The Dimension of Urban Design. Published by Routledge.

Calcating, A. (2012). The Need for a Cultural Landscape Theory: An architect's approach .Urban and Spatial Planning / Stadt- und Raumplanung. LIT Verlag.

Ertan, T. and Egercioglu, Y. (2016). "Historic City Center Regeneration: Case of Malaga and Kemeralti, Izmir". Juornal of Procedia-social and behavioral science. 233: 601-607.

Farnahad Consulting Engineers. (2011). "Development and construction project of Mashhad metropolis". Report: Development and Construction Vision, Objectives, Strategies, and Policies, 3rd. Mashhad.

Habibi, m. (2001). From Shar to the city: Historical Analysis Beyond Urban Design and Its Physical Appearance. University of Tehran Press.

Hough, M. (1990). Out of place: Restoring identity to the regional landscape. Yale University Press.

Haji Qassemi, K. (2005). Ganjnameh; cyclopaedia of Iranian Islamic Architecture, Bazaar Buildings. Vol.9. Rowzaneh Press.

Kaymaz, I. (2013). Urban Landscape and Identity. Ed. Ozyavuz, M. Advances in Landscape Architecture. InTech, Chapters published. 
Kheirabadi, M. (1991). Iranian Cities: Formation and Development. Syracuse University Press.

Madanipour, A. (1998). Tehran: The Making of a Metropolis(World Cities Series). Academy Press.

Mashhad Municipality. (2012). "The statistics of Mashhad demography, tourism and pilgrimage, 1st ed". Mashhad Municipality, Mashhad.

Mehdipour, A. Rashidi Nia, H. (2013)." Persian Bazaar and Its Imapct on Evolution of Historic Urban Cores- the Case of Isfahan". The Macrotheme Review. N.2 vol. 5.

O'hare, DJ. (1997)," Tourism and Small Coastal Settlements: A Cultural Landscape Approach for Urban Design". A thesis submitted in partial fulfilment of the requirements of Oxford Brookes University for the degree of Doctor of Philosophy.

Pourjafar, M. Amini, M and Varzane, E and Mahdavinejad, M. (2014). "Role of Bazaars as a Unifying Factor in Traditional Cities of Iran: The Isfahan Bazaar". Frontiers of Architectural Research,No.3.

Relph, E. (1976). Place and placelessness. Pion Limited. London

Rezvani, A. (2005). Finding Urban Identity in Mashhad. Ministry of Housing and Urban Development of Khorasan, Iran.

Soltanzade, H. (2004). Iranian Bazaars. Publication of Cultural Research Burea.

Tafahomi, R. (2007). Affect of Urban Design Aspects in the Urban Spaces Creation, Universiti Teknologi Malaysia Institutional Repository.

Tash. (2006). "The analaysis studies and the prepration of new comprehensive master plan for the ring and urban space of city center, Mashhad", Consulting Engineers company of TASH. N.2-105-11-99.

Whitehand, J. W. (2007, June). Conzenian urban morphology and urban landscapes. In INTERNATIONAL SPACE SYNTAX SYMPOSIUM (Vol. 6).

Zarabadi, S. and Ziyaee. M. (2008). "Sarshoor Area, New Function in Distressed Skeleton", First conference of Regeneration \& Revitalization of Urban Distressed Area ,Mashhad, Iran, 10-11 December 2008

Ziyaee, M. (2009). "Urban design in Sarshoor district of Mashhad city with the use of social \& economical models". Master thesis. Azad University of Iran-Science \& Research branchTehran.

Ziyaee, M. (2017). “Assessment of urban identity through a matrix of cultural landscapes". Juornal of Cities, In press. doi: 10.1016/j.cities.2017.10.021

\section{Resume}

Maryam Ziyaee is an architect, she holds a PhD in Urban and Architectural Design (Politecnico of Milano) and she was senior tutor of the Urban Design Course. 